\title{
COMPOSIÇÃO E DISTRIBUIÇÃO DOS MARCOINVERTEBRADOS BENTÔNICOS NA REPRESA DE GUARAPIRANGA - SP
}

\section{Daniele Cristina Schiavone ${ }^{1}$}

José Valdecir de Lucca ${ }^{2}$

Marcos Vinícius Nunes ${ }^{3}$

RESUMO: Os estudos ecológicos da comunidade dos macroinvertebrados bentônicos tem grande relevância devido à participação destes organismos nos processos funcionais dos sistemas aquáticos, particularmente no fluxo energético e na ciclagem de nutrientes. Outro aspecto importante se refere ao fato destes organismos serem bioindicadores da qualidade da água. $\mathrm{O}$ presente trabalho foi realizado nos meses de setembro de 2010 (Período seco) e fevereiro de 2012 (Período chuvoso), e teve como objetivo analisar a composição da comunidade bentônica comparando a estação chuvosa com a estação de seca, em 6 pontos da represa de Guarapiranga, SP, visando avaliar possíveis interferências antrópicas neste ecossistema. A Represa de Guarapiranga está situada na região sudoeste da Cidade de São Paulo, (23 43'S e $46^{\circ} 32^{\prime} \mathrm{W}$ ), em uma altitude de 742 metros, na Bacia do alto Tietê. Nos dias atuais contribui com aproximadamente 11 mil litros de água por segundo para o abastecimento de 3,7 milhões de pessoas. A coleta de material biológico foi realizada com Draga Van Veen, com área amostral

\footnotetext{
${ }^{1}$ Bióloga, Universidade de São Paulo. danischiavone@yahoo.com.br

${ }^{2}$ Biólogo, Universidade Federal de São Carlos. jvlucca@bol.com.br

${ }^{3}$ Biólogo, Universidade Federal de São Carlos. vnnybio@hotmail.com
} 
$377 \mathrm{~cm}^{2}$, de em tréplicas. Os organismos mais representativos numericamente foram os Diptera da família Chironomidae e os anelídeos da Classe Oligochaeta. Os representantes da família Chaoboridade (Diptera) teve destaque em todos os pontos da estação chuvosa. Os maiores valores de riqueza e diversidade foram registrados no ponto 6 (área de captação para abastecimento da SABESP) enquanto os menores valores para esses índices foram registrados nos pontos que recebem grande aporte de material proveniente da drenagem de áreas urbanas e rurais. Apoio financeiro: SABESP

Palavras-chave: Macroinvertebrados bentônicos, Biodiversidade, Represa Guarapiranga.

\section{INTRODUÇÃO}

De acordo com (SILVEIRA, 2004), os limnólogos associam as variações nas características ambientais dos rios com a alteração na estrutura da comunidade se insetos e outros invertebrados. Essas análises são utilizadas para testas hipóteses sobre os possíveis fatores que influenciam a estrutura da comunidade de rios, onde possibilita também modelar as respostas da biota às mudanças naturais e antrópicas no ambiente.

A eutrofização é acelerada pelo excesso de cargas poluidoras, levando a perda da qualidade da água, aumentando desaparecimento de várias espécies aquáticas e o custo do tratamento água (AZEVEDO, 2002).

Os macroinvertebrados bentônicos vêm sendo cada vez mais empregados, nos estudos de biomonitoramento de recursos hídricos, como uma ferramenta adequada para a avaliação da qualidade de água. Apesar de ter sido utilizada principalmente na América do Norte e Europa desde o século $X X$, sua utilização tem se expandido gradativamente nas últimas décadas.

Os macroinvertebrados aquáticos vivem sobre ou no interior de sedimentos, e possuem uma importância fundamental na dinâmica de nutrientes, na transformação de matéria orgânica e no fluxo de energia do ecossistema, além de participarem da cadeia alimentar de vários organismos aquáticos, especialmente de peixes (Rosenberg \& Resh, 1993). Alimentam-se principalmente de algas e microrganismos, situando-se assim numa 
posição intermediária na cadeia alimentar, tendo como seus principais predadores os peixes e outros vertebrados (SILVEIRA, 2004).

\section{DESENVOLVIMENTO}

A diversidade de macroinvertebrados que possuem interação com os ambientes aquáticos inclui organismos da Classe Insecta, Oligochaeta, Mollusca e Crustacea, sendo que os insetos constituem o grupo mais abundante na maioria desses sistemas. A colonização de um habitat é uma característica ecológica essencial para os organismos, necessária para a sobrevivência de muitas espécies, principalmente daquelas que apresentam um ciclo de vida relativamente curto ou ocupam ambientes fragmentados. (RODRIGUES, 2010).

Os representantes da família Chironomidae são consideramos os mais abundantes da comunidade bentônica, (PINDER, 1983. CALLISTO et al., 2002).

$\mathrm{Na}$ Cidade de São Paulo, o abastecimento de água é um objeto de grande preocupação para os profissionais da saúde pública e saneamento, devido à degradação da qualidade da água nos mananciais utilizados, nesse sentido existe a necessidade de investir em pesquisas básicas e aplicadas relacionadas à proteção ambiental (BEYRUTH, 1996).

O objetivo do trabalho, foi avaliar a composição e distribuição da comunidade bentônica em 6 pontos de coleta no Reservatório de Guarapiranga, SP, comparando-se a 2 períodos de sazonalidade, Chuvosa e Seca, e relacionar a influência das atividades antrópicas nesse ecossistema.

\section{MATERIAIS E MÉTODOS}

\section{1 Área de Estudo}

A represa de Guarapiranga está localizada na Bacia do Alto Tietê, na região sudoeste da área metropolitana da cidade de São Paulo ( 23043 S e 46 o 32W), em uma 


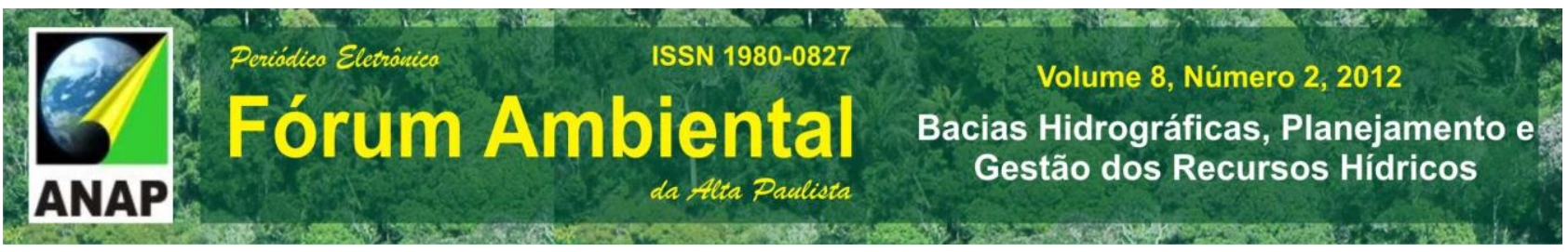

altitude de 742 metros, com área de drenagem de $640 \mathrm{Km} 2$ e área inundada de $33 \mathrm{Km} 2$. O volume total é de 194 milhões de metros cúbicos de água e sua profundidade média é de 5,7 metros (Cetesb, 2002).

A represa foi inicialmente utilizada para a geração de energia elétrica da Usina de Parnaíba, no rio Tietê e, a partir de 1927, tornou-se fonte de abastecimento para a região metropolitana de São Paulo. Atualmente, a represa constitui o segundo maior manancial do sistema de abastecimento da região metropolitana de São Paulo, fornecendo 11 mil litros de água por segundo para aproximadamente 3,7 milhões de pessoas (Cetesb, 2002). Esta abrange os municípios de Embu-Guaçu, Itapecerica da Serra e parte dos municípios de Cotia, Embu, Juquitiba, São Lourenço e São Paulo. A população que vive ao redor do reservatório de Guarapiranga aumentou em quase 40\% entre 1991 e 2000, e é estimada em 800 mil pessoas, sendo que em 2000, apenas a metade dos habitantes da região tinha algum sistema de coleta de esgotos e a maioria do esgoto coletado continua sendo despejada no reservatório. Em 2003, mais da metade da área total da bacia hidrográfica encontrava-se alterada por atividades humanas, sendo que $17 \%$ dessas alterações correspondem aos usos urbanos, e o restante diz respeito a usos diversos, como agricultura, mineração e solo exposto. (Web: de olho nos mananciais).

De modo geral este corpo hídrico tem sido cenário nos últimos anos de uma constante degradação ambiental, esta representada principalmente pela intensa urbanização, uso e ocupação de seu entorno de forma desordenada e pelo lançamento de efluentes gerados por cinco municípios e indústrias.

A melhoria das condições socioambientais da represa Guarapiranga é urgente, uma vez que a Região Metropolitana de São Paulo dispõe de poucas fontes de água com qualidade e quantidade adequadas para o abastecimento público. No inicio de 2006, ano do centenário da represa Guarapiranga, foi aprovada uma lei que tem como objetivo proteger e recuperar a região, sendo o marco inicial para reverter o processo de degradação e garantir o uso deste importante reservatório para o abastecimento público (Web: de olho nos manaciais).

\subsection{Caracterizações dos pontos de coleta}

VIII Fórum Ambiental da Alta Paulista, v. 8, n.2, 2012, p. 210-222. 


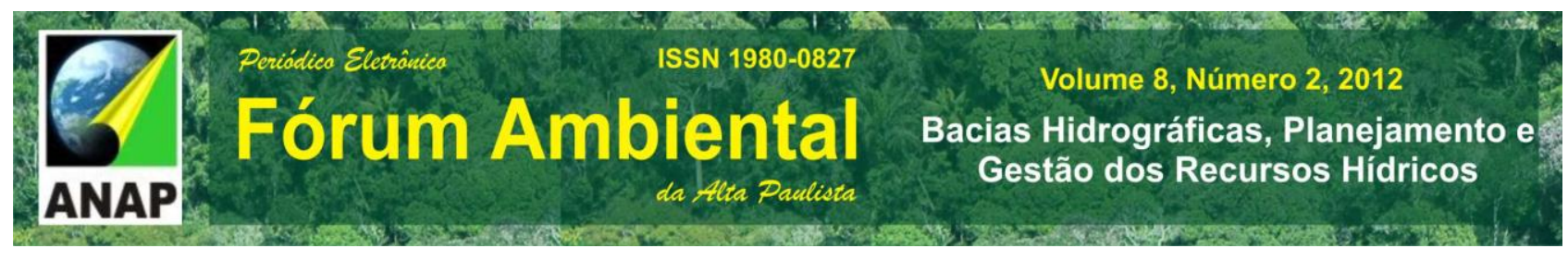

Foram selecionados seis pontos de coleta na represa de Guarapiranga, município de São Paulo (Figura 3), de modo que represente diferentes secções e tipos de interferência humana nesta represa.

Ponto 1: Pedras $\left(23^{\circ} 71^{\prime} 27,50^{\prime \prime}\right.$ e e $\left.46^{\circ} 71^{\prime} 98,40^{\prime \prime} \mathrm{W}\right)$ - localizado próximo à chegada do Rio das Pedras e córregos que drenam bacias urbanas densas;

Ponto 2: Parelheiros $\left(23^{\circ} 75^{\prime} 12,50^{\prime \prime} S\right.$ e $\left.46^{\circ} 72^{\prime} 76,10^{\prime \prime} \mathrm{W}\right)$ - localizado no braço do reservatório de Guarapiranga que recebe águas da transposição do reservatório Billings;

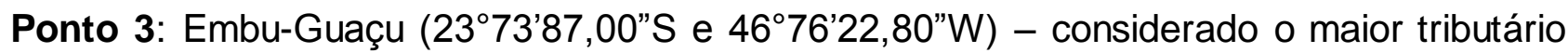
da represa de Guarapiranga com uma grande área de drenagem essencialmente rural;

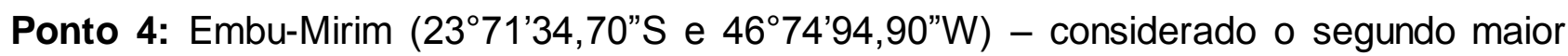
tributário de drenagem. A área de ocupação é mista. É considerado o braço que tem as florações mais intensas de algas;

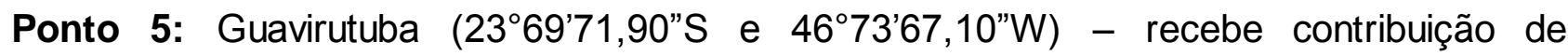
drenagem de área urbana, sendo que seu principal afluente passa por um processo de flotação para redução de carga;

Ponto 6: Captação $\left(23^{\circ} 67^{\prime} 99,20^{\prime \prime}\right.$ e e 46²7'69,50”W) - área de captação da SABESP

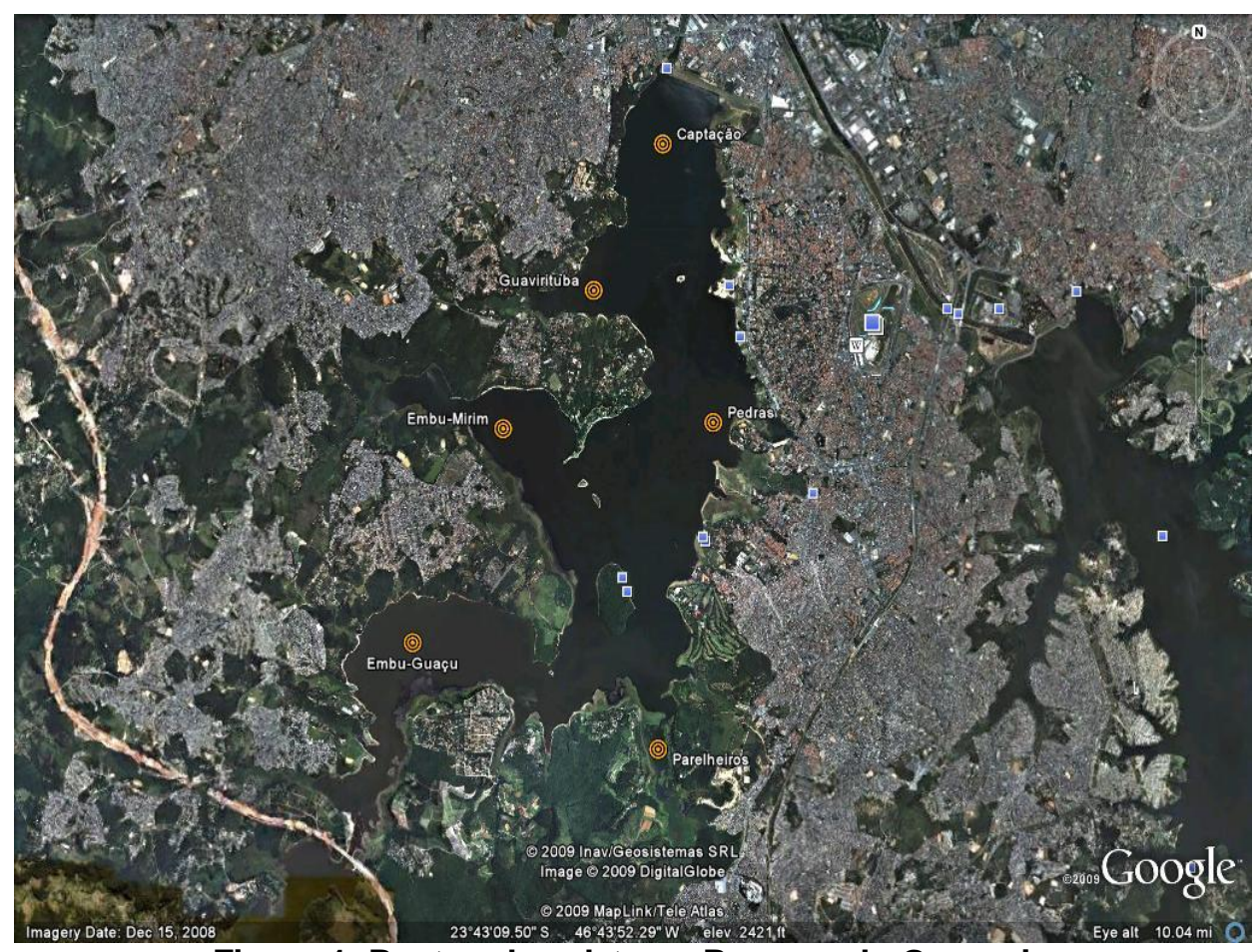

Figura 1. Pontos de coleta na Represa de Guarapiranga

VIII Fórum Ambiental da Alta Paulista, v. 8, n.2, 2012, p. 210-222. 


\subsection{Coleta de macroinvertebrados bentônicos e análises abióticas}

A coleta foi realizada, nos meses de Setembro de 2010, no período seco, e Fevereiro de 2012, o material foi coletado com a Draga Van Veen, com área amostral $377 \mathrm{~cm}^{2}$, em triplicata, em cada ponto de coleta. O material foi colocado em potes plásticos, fixados com formol a 4\%. Em laboratório os espécimes foram separadas, em bandejas, com iluminação, e os organismos fixadas em álcool $70 \%$ até a identificação. A identificação foi feita com literatura especializada. Foram realizadas medidas "in situ" das variáveis físicas e químicas ( $\mathrm{pH}$, oxigênio dissolvido e temperatura) com equipamento da marca Horiba modelo U-10.

\section{RESULTADOS E DISCUSSÃO}

Na tabela 1, são apresentados os valores das variáveis abióticas. De maneira geral o pH da água variou de ácido no período chuvoso notadamente no P1 captação a alcalino no período seco (P50 Parelheiros). Na estação chuvosa e seca observa-se anoxia em quase todos os pontos de amostragem evidenciando a péssima qualidade da água nesses locais.

Tabela 1. Variáveis Físicas e químicas

\begin{tabular}{llccc}
\hline & & PH & OD mg/L & Temp ${ }^{\circ}$ C \\
\hline \multirow{4}{*}{ Estação Chuvosa } & P1- Captação & 5,09 & 0 & 23,3 \\
& P11- Guavirutuba & 6,38 & 1,88 & 26,7 \\
& P26- Embu Mirim & 6,24 & 2,11 & 25,4 \\
& P50- Parelheiros & 6,26 & 0 & 26,3 \\
& P60- Santa Rita & 5,98 & 0 & 25,6 \\
& P63- Embu Guaçu & 5,74 & 0 & 23,9 \\
\hline \multirow{5}{*}{ Estação Seca } & P1- Captação & 5,6 & 0,5 & 18 \\
& P11- Guavirutuba & 6,8 & 0,2 & 19 \\
& P26- Embu Mirim & 6,7 & 0,5 & 19 \\
& P50- Parelheiros & 8,1 & 11,4 & 21 \\
& P60- Santa Rita & 6,6 & 1,1 & 20 \\
& P63- Embu Guaçu & 6,8 & 7,6 & 20 \\
\hline
\end{tabular}




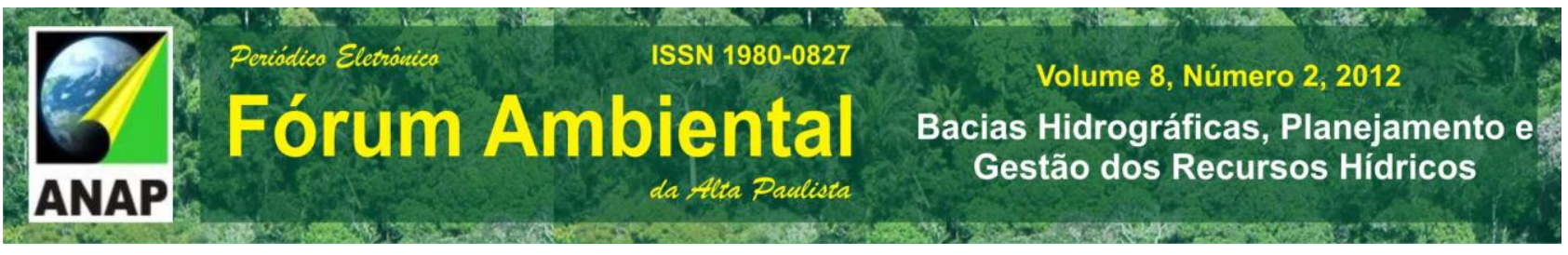

Considerando todos os pontos de amostragem, foram identificados um total de 1321 indivíduos, sendo 922 no período Chuvoso e 399 no período seco, distribuídos em 8 Classe/Ordem (Diptera, Ephemeroptera, Oligochaeta, Hirudinea, Bivalve, Gastropoda, Nematoda, Turbellaria) e 7 Famílias (Chironomidae, Ceratopogonidae, Chaoboridae, Polymitarcydae, Pisidiiae, Physidae,Planariidae). (Tabela 2). A Família Chironomidae e a Classe Oligochaeta foram os mais representativos de toda a fauna. No período seco, no Ponto 6, Chironomidae representou $50 \%$ do total da fauna bentônica. Segundo Callisto et al. (2002), os Chironomidae são considerados os mais abundantes na comunidade bentônica e normalmente dominam os ecossistemas aquáticos devido à capacidade de tolerar diferentes tipos de condições extremas (Cranston, 1995; Di Giovanni et al., 1996). O grupo é possivelmente o mais amplamente adaptado em relação aos demais insetos aquáticos, apresentando diversas adaptações ecológicas e biológicas que os torna aptos a explorar diferentes hábitats (Pinder, 1983). Vivem em todos os tipos de águas doces, frequentemente atingindo elevadas densidades populacionais. Suas larvas constituem importante item na dieta de peixes e também podem ser indicadoras da qualidade ambiental, com algumas espécies possuindo exigências ambientais específicas e outras sendo relativamente tolerantes a condições adversas. Segundo Olive \& Smith (1975) são os mais tolerantes à poluição orgânica quando comparados a outras larvas de Diptera. No período chuvoso, novamente no Ponto 6 , porém o táxon dominante foi Oligochaeta foi o mais abundante com $69 \%$ de toda a fauna. A eutrofização é visível na Represa de Guarapiranga, com níveis de poluição acima da média, esgotos lançados na água, sem tratamento e lixos irregulares, causam o crescimento de aguapés e algas. (Estadão, 2010). A maior abundância de táxons foi registrada no período chuvoso contrariando vários estudos já realizados. Provavelmente isso ocorreu devido à entrada de material alóctone proveniente das chuvas, proporcionando condições favoráveis para o desenvolvimento e estabelecimento da comunidade bentônica nesse período, como apresentado na Figura 2. 
Tabela 2. Composição da fauna bentônica distribuída em todos os pontos de amostragem.

\begin{tabular}{|c|c|c|c|c|c|c|c|c|c|c|c|c|c|c|c|c|c|}
\hline \multirow[b]{2}{*}{ CLASSE/ORDEM } & \multirow[b]{2}{*}{ FAMÍLIA } & \multicolumn{6}{|c|}{ PERÍODO SECO } & \multirow[b]{2}{*}{ AA } & \multirow[b]{2}{*}{$A B \%$} & \multicolumn{6}{|c|}{ PERÍODO CHUVOSO } & \multirow[b]{2}{*}{ AA } & \multirow[b]{2}{*}{$A B \%$} \\
\hline & & P1 & $\mathbf{P 2}$ & P3 & P4 & P5 & P6 & & & $\mathbf{P 1}$ & P2 & P3 & P4 & P5 & P6 & & \\
\hline \multirow[t]{3}{*}{ Diptera } & Chironomidae & 0 & 2 & 1 & 0 & 2 & 195 & 200 & 50 & 0 & 22 & 0 & 52 & 0 & 2 & 76 & 8 \\
\hline & Ceratopogonidae & 0 & 0 & 0 & 0 & 0 & 1 & 1 & 0 & 0 & 0 & 0 & 0 & 0 & 0 & 0 & - \\
\hline & Chaoboridae & 0 & 0 & 0 & 5 & 17 & 2 & 24 & 6 & 40 & 9 & 48 & 20 & 65 & 4 & 186 & 20 \\
\hline Ephemeroptera & Polymitarcyidae & 0 & 0 & 0 & 0 & 0 & 4 & 4 & 1 & 0 & 0 & 0 & 0 & 0 & 0 & 0 & - \\
\hline Oligochaeta & & 30 & 0 & 0 & 1 & 45 & 71 & 147 & 37 & 96 & 63 & 18 & 10 & 206 & 245 & 638 & 69 \\
\hline Hirudinea & & 0 & 0 & 1 & 0 & 2 & 15 & 18 & 5 & 0 & 1 & 0 & 9 & 0 & 2 & 12 & 1 \\
\hline Bivalve & Pisidiae & 0 & 0 & 0 & 0 & 1 & 1 & 2 & 1 & 0 & 0 & 0 & 0 & 0 & 0 & 0 & - \\
\hline Gastropoda & Physidae & 1 & 0 & 0 & 0 & 0 & 0 & 1 & 0 & 0 & 0 & 0 & 0 & 0 & 0 & 0 & - \\
\hline Nematoda & & 0 & 0 & 2 & 0 & 0 & 0 & 2 & 1 & 1 & 0 & 0 & 3 & 0 & 4 & 8 & 1 \\
\hline Turbellaria & Planariidae & 0 & 0 & 0 & 0 & 0 & 0 & - & - & 0 & 0 & 0 & 0 & 0 & 1 & 1 & 0 \\
\hline Pupa ( Diptera) & & 0 & 0 & 0 & 0 & 0 & 0 & - & - & 0 & 1 & 0 & 0 & 0 & 0 & 1 & 0 \\
\hline \multicolumn{2}{|c|}{ Total de indivíduos } & 31 & 2 & 4 & 6 & 67 & 289 & 399 & 100 & 137 & 96 & 66 & 94 & 271 & 258 & 922 & 100 \\
\hline \multicolumn{2}{|c|}{ Riqueza de táxons } & 2 & 1 & 3 & 2 & 5 & 7 & - & - & 3 & 5 & 2 & 5 & 2 & 6 & - & - \\
\hline
\end{tabular}

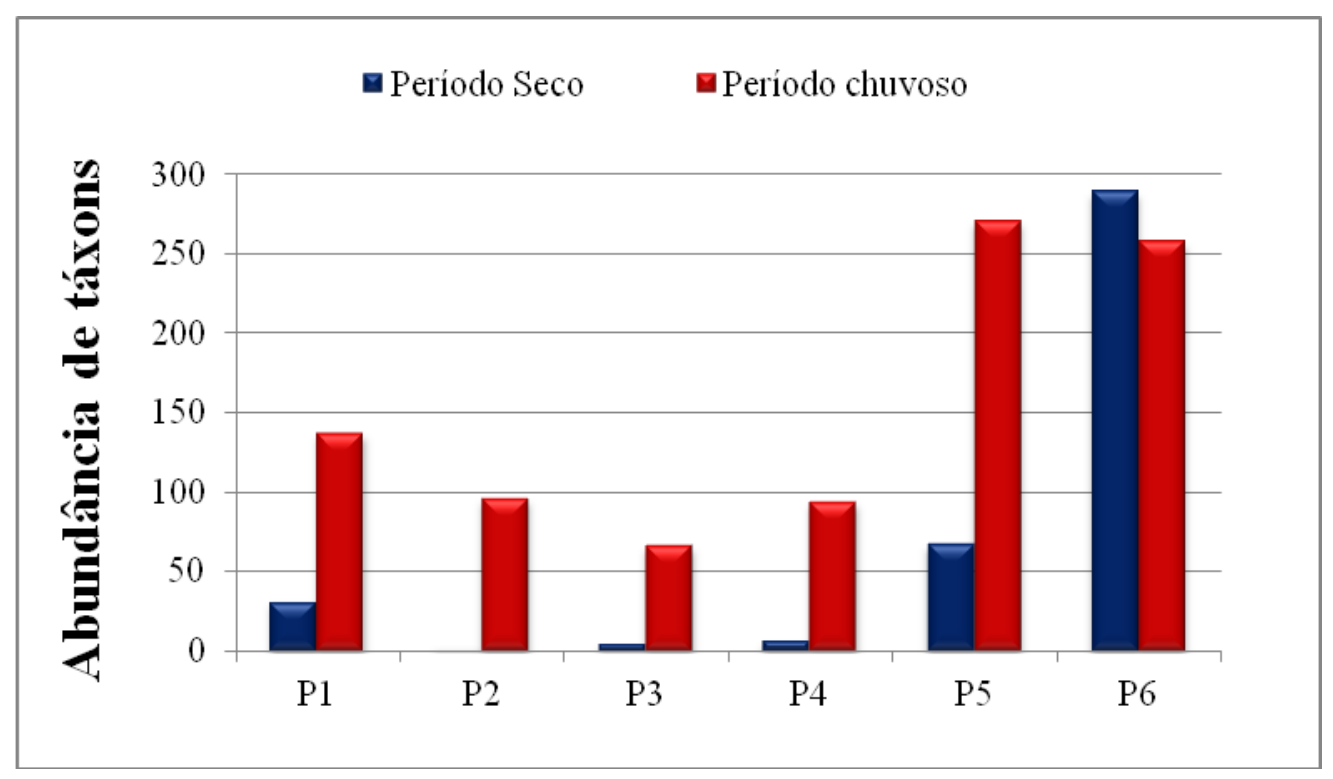

Figura 2: Abundância de táxons distribuídas nas 2 estações amostradas, Seca e Chuvosa.

A densidade numérica (Ind/ $/ \mathrm{m}^{2}$ ) (Figura 3) apresenta a maior densidade no período Chuvoso, assim como abundância de indivíduos. De acordo com os autores (Howmiller \& 
Beeton, 1971), os altos valores de abundância e densidade registrados para os Oligochaeta podem indicar um elevado grau de poluição da água. Além disso, ocorrem geralmente em altas densidades, apresentam ciclo de vida curto e biomassa elevada, 0 que lhes confere um importante papel no fluxo energético (Coffman \& Ferrington, 1998). Este grupo tem despertado grande interesse, principalmente por ocorrer em águas poluídas, ricos em matéria orgânica, em lagos, rios e estuários, sendo considerados bons indicadores ambientais (Wetzel, 1983). (Tabela 3)

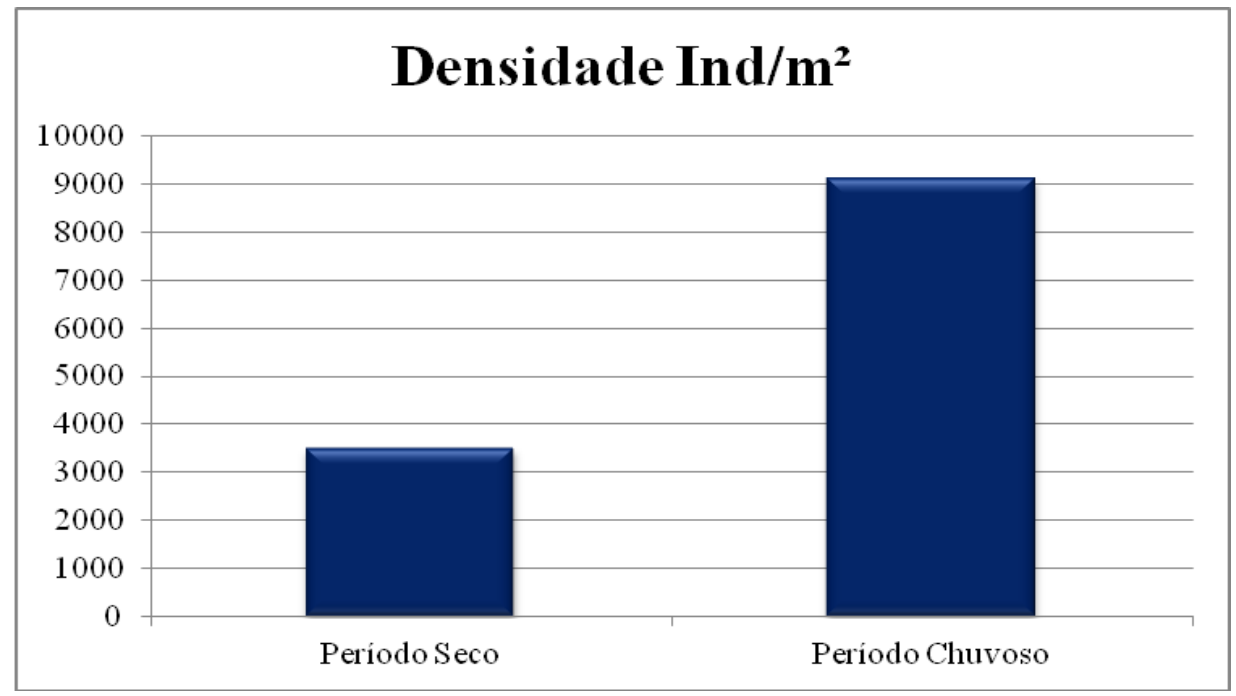

Figura 3. Densidade numérica ( $\mathrm{Ind} / \mathrm{m}^{2}$ ) entre os períodos de sazonalidade (Seco e Chuvoso)

Chaoboridae, teve destaque com a segunda maior densidade entre os outros táxons no período Chuvoso, sendo representado em todos os pontos. Por habitarem tanto ambientes lênticos quanto lóticos, esses organismos são predadores, apresentam migração vertical, são característicos de ambientes profundos e estão adaptados a ambientes totalmente anóxicos (Lisboa, 2009). No caso da estação chuvosa, provavelmente o reservatório teve sua profundidade aumentada, assim proporcionando elevada abundância dessa família. 
Tabela 3. Densidade numérica ( $\mathrm{Ind} / \mathrm{m}^{2}$ ) dos pontos de amostragem períodos Seco e Chuvoso.

\begin{tabular}{|c|c|c|c|c|c|c|c|c|c|c|c|c|c|c|c|}
\hline \multirow[b]{2}{*}{ ORDEM } & \multirow[b]{2}{*}{ FAMÍLIA } & \multicolumn{6}{|c|}{ PERÍODO SECO } & \multirow[b]{2}{*}{ Dens(Ind/m²) } & \multicolumn{6}{|c|}{ PERÍODO CHUVOSO } & \multirow[b]{2}{*}{ Dens(Ind/m²) } \\
\hline & & P1 & P2 & P3 & P4 & P5 & P6 & & P1 & P2 & P3 & P4 & P5 & P6 & \\
\hline \multirow[t]{3}{*}{ Diptera } & \multirow{4}{*}{$\begin{array}{c}\text { Chironomidae } \\
\text { Ceratopogonidae } \\
\text { Chaoboridae } \\
\text { Polymitarcyidae }\end{array}$} & 0 & 2 & 1 & 0 & 2 & 195 & 1978,24 & 0 & 22 & 0 & 52 & 0 & 2 & 751,73 \\
\hline & & 0 & 0 & 0 & 0 & 0 & 1 & 9,89 & 0 & 0 & 0 & 0 & 0 & 0 & - \\
\hline & & 0 & 0 & 0 & 5 & 17 & 2 & 237,39 & 40 & 9 & 48 & 20 & 65 & 4 & 1839,76 \\
\hline Ephemeroptera & & 0 & 0 & 0 & 0 & 0 & 4 & 39,56 & 0 & 0 & 0 & 0 & 0 & 0 & - \\
\hline Oligochaeta & & 30 & 0 & 0 & 1 & 45 & 71 & 1454,01 & 96 & 63 & 18 & 10 & 206 & 245 & 6310,58 \\
\hline Hirudinea & & 0 & 0 & 1 & 0 & 2 & 15 & 178,04 & 0 & 1 & 0 & 9 & 0 & 2 & 118,69 \\
\hline Bivalve & \multirow{3}{*}{$\begin{array}{l}\text { Pisidiiae } \\
\text { Physidae }\end{array}$} & 0 & 0 & 0 & 0 & 1 & 1 & 19,78 & 0 & 0 & 0 & 0 & 0 & 0 & - \\
\hline Gastropode & & 1 & 0 & 0 & 0 & 0 & 0 & 9,89 & 0 & 0 & 0 & 0 & 0 & 0 & - \\
\hline Nematoda & & 0 & 0 & 2 & 0 & 0 & 0 & 19,78 & 1 & 0 & 0 & 3 & 0 & 4 & 9,89 \\
\hline Turbellaria & \multirow[t]{2}{*}{ Planariidae } & 0 & 0 & 0 & 0 & 0 & 0 & - & 0 & 0 & 0 & 0 & 0 & 1 & 79,13 \\
\hline Pupa (Diptera) & & 0 & 0 & 0 & 0 & 0 & 0 & - & 0 & 1 & 0 & 0 & 0 & 0 & 9,89 \\
\hline
\end{tabular}

\section{CONCLUSÕES}

- Registrou-se anoxia em quase todos os pontos do reservatório de Guarapiranga evidenciando que este sistema encontra-se impactado.

- Verificou-se uma baixa riqueza taxonômica e a dominância de Chironomidae e Oligochaeta em praticamente todos os pontos estudados.

- A composição dos macroinvertebrados bentônicos registrado no presente estudo refletem as características do local, ou seja, um sistema eutrofizado e impactado onde só os espécimes tolerantes conseguem sobreviver. 


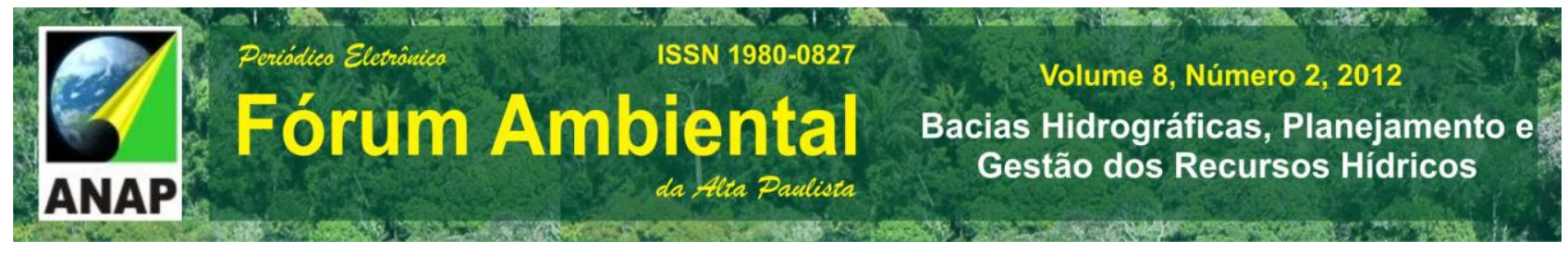

\section{REFERÊNCIAS}

AZAVEDO, M.T.P. (2002). Cianobactérias Formadoras de Florações: Biodiversidade em Águas de Abastecimento. In: Reunião Brasileira de Ficologia, 9., 2002.Aracruz. Resumos. Aracruz: Sociedade Brasileira de Ficologia, p.19,2002.

CALLISTO, M. et al. Aplicação de um protocolo de avaliação rápida de diversidade de habitats em atividades de ensino e pesquisa (MG-RJ). Acta Limnológica Brasiliensis, v. 34, p. 91-98, 2002.

CALLISTO, M., Moretti, M. \& Goulart, M. Macroinvertebrados bentônicos como ferramenta para avaliar a saúde de riachos. Revista Brasileira de Recursos Hídricos, 1: 71-82, 2002

CETESB. Manual de gerenciamento de áreas contaminadas. CETESB, GTZ. 2.ed. São Paulo : CETESB, 2002.

COFFMAN, W.P., \& FERRINGTON, L.. Chironomidae. In: An Introduction to the Aquatic Insects of North America, 3rd Edition, MERRITT, R., and CUMMINS, K.W., Ed. Kandall-Hunt, Dubuque, lowa, p. 635-754,1998.

CRANSTON, P. S.,. Introduction to the Chironomidae. In: P. ARMITAGE, P. S. CRANSTON \& C. V. PINDER (eds.), The Chironomidae: the biology and ecology of non-biting midges. CHAPMAN \& HALL, New York, p. 1-7, 1995.

DI GIOVANNI, M.V., Goretti, E. \& TAMANTI, V. Macrobenthos in Montedoglio Reservoir, central Italy. Hidrobiologia, 321: $17-28,1996$

Site da Web. Jornal Estadão: disponível em: http://blogs.estadao.com.br/olhar-sobre-omundo/represa-guarapiranga/. Acessado em 23/12/2012. 
HOWMILLER, RP. and BEETON, AM. Biological evaluation of environmental quality, GREEN BAY, LAKE MICHIGAN. J. Water Pollut. Con. F. vol. 42, no. 3, p. 123-133, 1971.

LISBOA, L.K. Estrutura e Composição da fauna de macroinvertebrados bentônicos da Lagoa do Peri, Florianópolis, SC. TCC. Universidade de Santa Catarina. 43p,2009.

OLIVE, J.H. \& Smith, K.R.. Benthic macroinvertebrates as indexes of water qualitiy in Scioto River Basin,Ohio Biol. Surv. 5 (2), 124p, 1975.

PINDER, L.C.V. The larvae of Chironomidae (Díptera) of the Holartic region- Introduction. Entomologica Scandinavica Supplement, v. 19, p. 7-10, 1983.

PÉREZ, G. R. Guía para el estudio de los macroinvertebrados acuáticos Del Departamento de Antioquia. Universidad de Antioquia, p. 217, 1996.

RODRIGUES, G.N. Interação macroinvertebrados-substrato: qual substrato artificial é mais adequado à colonização pela comunidade natural presente no corpo d'água . Monografia (Ufscar). 30 p, 2010.

ROCHA, S. M. PIVELLI, R.P. Macroinvertebrados bentônicos como indicadores de poluição na represa do guarapiranga - são paulo - brasil. XXVII Congresso Interamericano de Engenharia Sanitária e Ambiental. ABES - Associação Brasileira de Engenharia Sanitária e Ambiental, 2000.

ROSEMBERG, D.M. \& RESH, V.H.. Introduction to freshwater biomonitoring and benthic macroinvertebrates. Freshwater Biomonitoring and Benthic Macroinvertebrates (eds D.M. ROSENBERG \& V.H. RESH). CHAPMAN \& HALL, London. 1-9, 1993.

SILVEIRA, M. P. Aplicação do biomonitoramento da qualidade da água em rios. Meio Ambiente. Documentos n. 36, Embrapa, 68 p, 2004. 
Web Site: De olho nos mananciais, disponível em: http://www.mananciais.org.br/category/guarapiranga/ acessado em 23/10/2012.

WETZEL, R.G. Limnology, 2"d Edition. Saunders College Publishing, Philadelphia, PA, 1983. 